\title{
Fabrication of Porous Stainless Steel 316L for Biomedical Applications
}

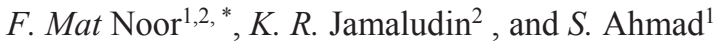 \\ ${ }^{1}$ Faculty of Mechanical \& Manufacturing Engineering, Universiti Tun Hussein Onn Malaysia \\ (UTHM), 86400 Parit Raja, Batu Pahat, Johor, Malaysia \\ ${ }^{2}$ UTM Razak School of Engineering \& Advanced Technology, Universiti Teknologi Malaysia Kuala \\ Lumpur, 54100 Jalan Semarak, Kuala Lumpur, Malaysia.
}

\begin{abstract}
Porous metals are very attractive materials for biomedical application as the physical and mechanical properties of these materials can be tailored similarly to the natural bone. In this work, porous stainless steel 316L has been fabricated by foam replication method. This method offers a lot of advantages including of easy processing technique, very economic, does not involve the use of toxic chemical and capable of producing porous structure that almost similar to natural bone. The porous stainless steel 316L (SS316L) samples were prepared by varying the SS316L composition from $40 \mathrm{wt} \%$ to $60 \mathrm{wt} \%$. Sintering process was carried out at $1250^{\circ} \mathrm{C}$ in a vacuum furnace. The microstructure and pore size were observed and determined through Scanning Electron Microscope (SEM). Archimedes method was used to measure the samples density, while compression test was carried out to determine the compressive strength and elastic modulus. The average pore size for samples with 50 $\mathrm{wt} \%$ and $60 \mathrm{wt} \% \mathrm{SS} 316 \mathrm{~L}$ are $268 \mu \mathrm{m}$ and $299 \mu \mathrm{m}$ respectively. Samples with $40 \mathrm{wt} \% \mathrm{SS} 316 \mathrm{~L}$ experienced the largest shrinkage which is $33 \%$ while the sample with $60 \mathrm{wt} \% \mathrm{SS} 316 \mathrm{~L}$ experienced the smallest shrinkage which is $21 \%$. The density and porosity of the porous SS316L with $50 \mathrm{wt} \%$ $\mathrm{SS} 316 \mathrm{~L}$ are $0.43 \mathrm{~g} / \mathrm{cm} 3$ and $93.6 \%$ respectively, and for porous SS316L with $60 \mathrm{wt} \% \mathrm{SS} 316 \mathrm{~L}$ are $0.69 \mathrm{~g} / \mathrm{cm} 3$ and $89.2 \%$ respectively. The modulus of elasticity and compressive strength for porous SS316L with $60 \mathrm{wt} \%$ SS316L are $0.46 \mathrm{GPa}$ and $56 \mathrm{MPa}$ respectively. All these properties are in the range of the natural bone properties. Besides, the cytotoxicity test showed that this porous SS316L does not have a cytotoxic potential for biomedical implant.
\end{abstract}

\section{Introduction}

Porous metals that are commonly used for biomedical applications are titanium and titanium alloys, Cobalt Chrome and nitinol shape memory alloys and stainless steel $316 \mathrm{~L}$ [1]. Amongst all, stainless steel $316 \mathrm{~L}$ is the longest being applied in the biomedical implant which is since 1920's [1, 2]. Stainless steel 316L are low cost, easy availability and processing, good workability, high fatigue life and fracture toughness [1, 3, 4]. However,

\footnotetext{
*Corresponding author: fazimah@uthm.edu.my
} 
the modulus of elasticity of stainless steel $316 \mathrm{~L}$ is much higher compared to natural bone which is $193 \mathrm{GPa}$ for stainless steel $316 \mathrm{~L}$ and $0.1-20 \mathrm{GPa}$ for natural bone. One of the most effective ways to reduce the stiffness mismatches or stress shielding effect between the natural bone and medical implant is through the using of porous metals or metal foams [5].

Foam replication method is basically a simple, easy and cheap method. This method capable of producing metal foams with a porous structure that most resembles cancellous bone [6]. However, every single processing step needs for proper study and exploration in order to obtain defect-free structures with optimum properties [7]. Figure 1 shows that the microstructure of the natural bone is almost similar to the microstructure of polyurethane (PU) foam used as a sacrificial template for this work. The open and interconnected pores will provide a stable fixation through the bone ingrowth into the pores between the metal implant and natural bone [8].

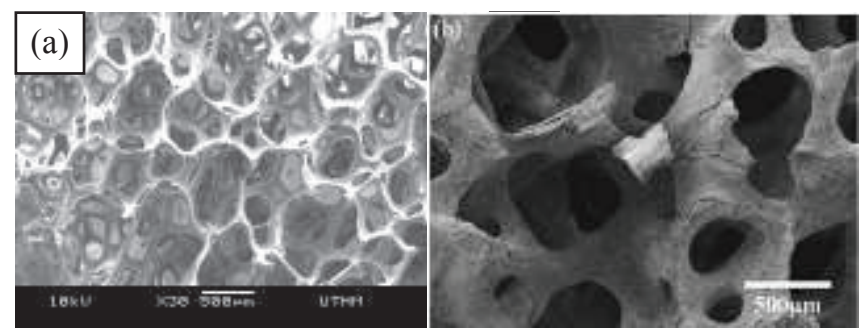

Fig. 1. Microstructure of the (a) polyurethane foam (PU) template and (b) natural bone [17] .

One of the major factors that determine the successful of a biomaterial or an implant is the properties of the biomaterials. The metal implants produced should have the properties similar to the natural bone. Table 1 listed some of the characteristics and properties of the natural bone.

Table 1. Properties of natural bone[8,9]

\begin{tabular}{|c|c|c|c|c|}
\hline $\begin{array}{c}\text { Compressive } \\
\text { strength } \\
(\mathrm{MPa})\end{array}$ & $\begin{array}{c}\text { Young's } \\
\text { Modulus } \\
(\mathrm{GPa})\end{array}$ & $\begin{array}{c}\text { Pore } \\
\text { size } \\
(\mu \mathrm{m})\end{array}$ & $\begin{array}{c}\text { Porosity } \\
(\%)\end{array}$ & $\begin{array}{c}\text { Density } \\
\left(\mathrm{g} / \mathrm{cm}^{3}\right)\end{array}$ \\
\hline $2-200$ & $0.1-20$ & $50-500$ & $50-90$ & $0.05-1.0$ \\
\hline
\end{tabular}

\section{Methodology}

The SS316L slurry with the composition of 40 wt.\%, 50 wt.\% and 60 wt.\% SS316L was prepared by mixing with $2.5 \mathrm{wt} . \%$ polyethylene glycol (PEG), 2.5 wt.\% methyl cellulose $(\mathrm{CMC})$ and distilled water using a mechanical stirrer for 2 hours. PU foam templates were then impregnated in the slurry and the excessive slurry was manually squeezed out. After that, the coated PU foam templates were dried in the oven at $30^{\circ} \mathrm{C}$ for 24 hours. The dried templates were then sintered at a temperature of $1250^{\circ} \mathrm{C}$ for 90 minutes.

The microstructure of the porous SS316L was examined by using Scanning Electron Microscope. The density and porosity were measured by using Archimedes principle. 
Compression test was performed according to ISO 13314: Mechanical testing of metalsDuctility testing - Compress a speed rate of $0.5 \mathrm{~mm} / \mathrm{min}$ by using the universal testing machine (UTM), Shimadzu AG-1 10kN. Cytotoxicity test was evaluated according to ISO 10993-5:2009 "Biological evaluation of medical devices. Part 5-Tests for in vitro cytotoxicity" for the sample with the highest SS316L composition (60 wt.\%). The test item was tested in triplicates at six concentrations of $0.2,0.1,0.05,0.025,0.0125$, and 0.00625 $\mathrm{g} / \mathrm{mL}$. The treatment was carried out at $37 \pm 1{ }^{\circ} \mathrm{C}$ in a carbon dioxide incubator and assessment carried out after 24 hours incubation.

\section{Results and Discussion}

Figure 2 shows the digital images of the SS316L foam samples before and after sintering. The sample before sintering is shown in Figure 1 (a) with a cubic shape of $15 \mathrm{~mm}$. The sample with $40 \mathrm{wt} \%$ SS316L experienced the most significant shrinkage and shape deformation. It is followed by the sample with $50 \mathrm{wt} . \% \mathrm{SS} 316 \mathrm{~L}$. Only the sample with 60 wt.\% SS316L compositions retains its original shape and slightly shrinks. Therefore only this sample has been forwarded for the compression test. Based on the samples dimension taken before and after sintering, it was found that the sample with $60 \mathrm{wt} . \%$ SS316L shrink about $20.62 \%$, sample with 50 wt. $\%$ SS316L shrink about $29.76 \%$ while the sample with 40 wt. $\%$ SS316L shrink about $32.56 \%$. The high shrinkage percentage for samples with 40 wt.\% and 50 wt.\% SS316L is due to the serious shape deformation. The shrinkage percentage increases with the decreasing of the SS316L composition. At lower SS316L composition, there were not enough SS316L particles to fully coat the PU foam struts. As the PU foam template burn out during sintering, the struts were seriously collapsed and large shrinkage occurs inside the SS316L foam [10]. This shrinkage was also due to the elimination of pores during the sintering process [11]. Most of the porous materials shrink and experienced net-shape deformation or distortion during sintering [12].

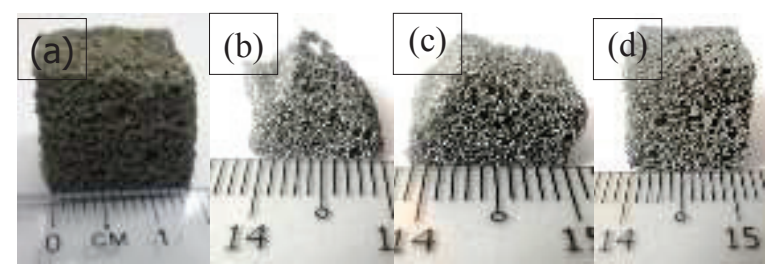

Fig. 2. Digital images of (a) PU foam template coated with SS316L slurry before sintering, (b) sintered of $40 \mathrm{wt} \% \mathrm{SS} 316 \mathrm{~L}$, (c) sintered of $50 \mathrm{wt} \% \mathrm{SS} 316 \mathrm{~L}$, and (d) sintered of $60 \mathrm{wt} \% \mathrm{SS} 316 \mathrm{~L}$

The effect of increasing the SS316L composition on the samples' density and porosity can be seen in Figure 3. From the figure, the density increased while porosity decreased as the SS316L composition has been reduced from $50 \mathrm{wt} . \%$ to $40 \mathrm{wt} . \%$. It is related to the higher amount of closed pores found in the samples especially for sample with $40 \mathrm{wt} . \%$ SS316L composition. The samples were totally collapsed after sintering, no open pores produced and the samples become densified [13]. Nevertheless, the samples density increased while porosity decreased when the SS316L composition was increased from 50 wt. $\%$ to 60 wt. $\%$, which was agreed with the result found by the previous researcher [13]. The density of the samples with $50 \mathrm{wt} \%$ and $60 \mathrm{wt} . \% \mathrm{SS} 316 \mathrm{~L}$ are $0.43 \mathrm{~g} / \mathrm{cm}^{3}$ and 0.60 $\mathrm{g} / \mathrm{cm}^{3}$ respectively. While the porosity percentage for the sample with $50 \mathrm{wt} . \%$ and $60 \mathrm{wt} . \%$ 
SS316L are $93.6 \%$ and $89.2 \%$ respectively. The struts size of sample with 60 wt. $\%$ SS316L in figure 4 (c) is thicker compared to sample with $50 \mathrm{wt} . \% \mathrm{SS} 316 \mathrm{~L}$ as shown in figure 4 (b). The density and porosity of these samples are in the range of the natural bone's density and porosity $[8,9]$.

Figure 4 shows the microstructure of the porous SS316L at different SS316L composition. There are more open pores found in the sample with higher SS316L composition. As can be seen in Figure 3 (a), the sample with 40 wt.\% SS316L composition consisted of mostly closed pores due to the formation of liquid films bridging the pores. M.J. Matos et al [14] proved that the presence of closed cell windows contributes to the overall shrinkage. However, as the SS316L composition was increased to $50 \mathrm{wt} . \%$ and 60 wt.\% as shown in Figure 4 (b) and 4 (c), almost all pores are open and interconnected throughout the samples with an average pore size of $268 \mu \mathrm{m}$ and $299 \mu \mathrm{m}$ respectively. The average pore size for samples with $60 \mathrm{wt} . \% \mathrm{SS} 316 \mathrm{~L}$ is slightly higher than the samples with 50 wt. $\%$ SS316L since the shrinkage percentage for this sample is lower than the sample with 50 wt. $\%$ SS316L.

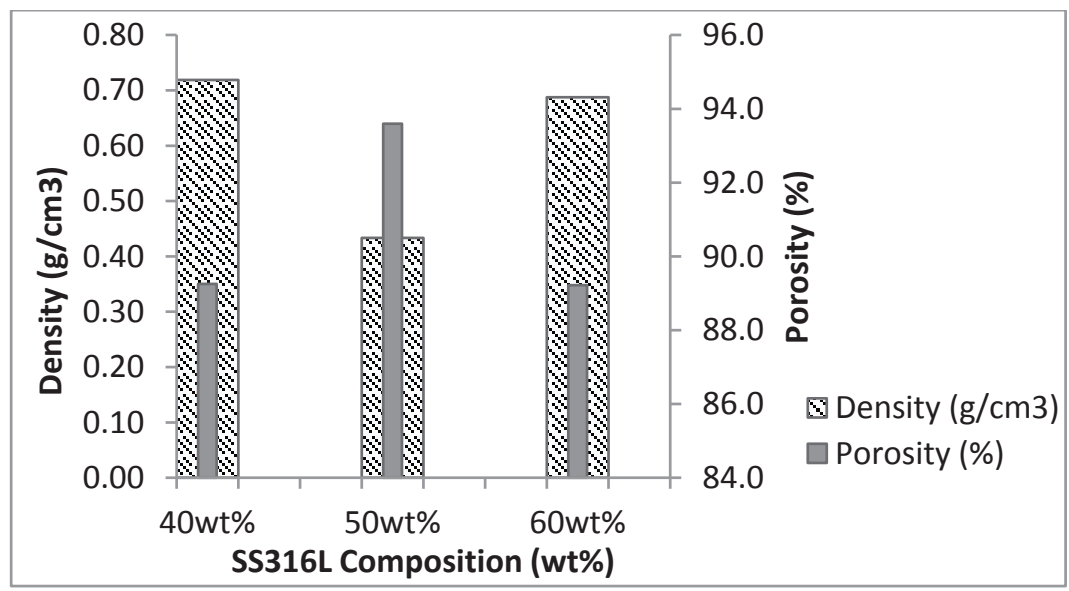

Fig. 3. Density and porosity percentage of porous stainless steel 316L at different SS316L composition

In general, the slurry should have a suitable viscosity to flow into the PU foam network and uniformly covering the PU foam and stay adhered on the PU foam struts until the sintering process. If the SS316L composition is too high, the slurry will become too thick. Thus, it will be more difficult for the slurry to enter the PU foam and the excessive slurry after the impregnation also could not be squeezed out easily. Nevertheless, if the SS316L composition is too low, the slurry will become too thin. Thus, there will be a limited amount of SS316L successfully coated and adhered on the PU foam struts and therefore it is difficult to maintain the shape of porous SS316L after the PU foam is burned out during the sintering [15].

According to J. Banhart et al [16], in order to evaluate the potential application of porous materials, it is very important to determine their compression behaviours. As for examples, the compression strength and the stress-strain curve. In this work, from the compression test, the modulus of elasticity and compressive strength obtained for sample with 60 wt.\% SS316L are $0.46 \mathrm{GPa}$ and $56 \mathrm{MPa}$ respectively. This results are very promising since this properties are in the range of the natural bone properties. 

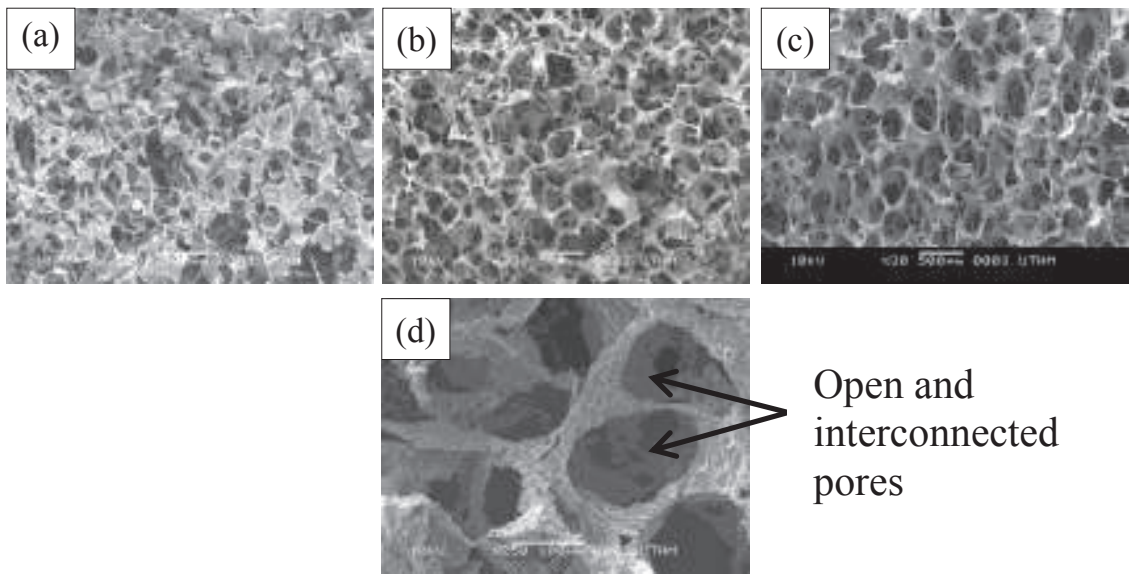

Open and interconnected pores

Fig. 4. Microstructure of the porous stainless steel $316 \mathrm{~L}$ at (a) $40 \mathrm{wt} \% \mathrm{SS} 316 \mathrm{~L}$, (b) $50 \mathrm{wt} \%$ $\mathrm{SS} 316 \mathrm{~L}$, (c) $60 \mathrm{wt} \% \mathrm{SS} 316 \mathrm{~L}$ and (d) is the microstructure of $60 \mathrm{wt} \% \mathrm{SS} 316 \mathrm{~L}$ at higher magnification.

Biocompatibility is associated with the corrosion behaviour of a material in the body and the tendency for this material to discharge possible toxic ions. Table 2 presents the results of the cytotoxicity tests of this porous SS316L. Positive and negative controls were included in this study to verify the proper functioning of the test system. The result showed that the toxicity levels were 0 after cultivation for 24 hours. This indicated that performance of SS316L foam is stable and without poisonous substance precipitation and other obvious side effects on cells. Cytotoxicity assay showed that this porous SS316L does not have a cytotoxic potential.

Table 2. Summary of cytotoxic grading on cultures

\begin{tabular}{|c|c|c|}
\hline Test extracts and controls & Grade & Reactivity \\
\hline Test extract, $0.2 \mathrm{~g} / \mathrm{mL}$ & $0-0-0$ & None \\
\hline Test extract, $0.1 \mathrm{~g} / \mathrm{mL}$ & $0-0-0$ & None \\
\hline Test extract, $0.05 \mathrm{~g} / \mathrm{mL}$ & $0-0-0$ & None \\
\hline Test extract, $0.025 \mathrm{~g} / \mathrm{mL}$ & $0-0-0$ & None \\
\hline Test extract, $0.0125 \mathrm{~g} / \mathrm{mL}$ & $0-0-0$ & None \\
\hline Test extract, $0.00625 \mathrm{~g} / \mathrm{mL}$ & $0-0-0$ & None \\
\hline Medium control & $0-0-0$ & None \\
\hline Negative control & $0-0-0$ & None \\
\hline Positive control & $4-4-4$ & Severe \\
\hline
\end{tabular}

\section{Conclusions}

It is possible to produce porous $\mathrm{SS} 316 \mathrm{~L}$ by foam replication method for biomedical implants since the properties of the porous SS316L produced in this work similar to the natural bone properties and the cytotoxicity test also shows that this porous SS316L has good cytocompatibility. However, adding the appropriate amount of SS316L composition during the slurry preparation is very important. The slurry should not become neither too thick nor too thin. The density of the samples is in the range of $0.43 \mathrm{~g} / \mathrm{cm}^{3}$ to $0.60 \mathrm{~g} / \mathrm{cm}^{3}$. The porosity percentage of the samples was found the range of $89.2 \%$ to $93.6 \%$. Whereas, 
the average pores size of porous SS316L is in the range of $268 \mu \mathrm{m}$ to $299 \mu \mathrm{m}$. The modulus of elasticity and compressive strength for porous SS316L with 60 wt.\% SS316L are 0.46 $\mathrm{GPa}$ and $56 \mathrm{MPa}$ respectively. In the future work, the SS316L composition will be increased and the compression strength of the porous SS316L produced will be studied further.

\section{Acknowledgement}

The authors would like to acknowledge Malaysian Ministry of Education (KPM) for the financial support through Exploration Research Grant Scheme (ERGS-E028). The first author would also like to thank the University Tun Hussein Onn Malaysia (UTHM) for funding her $\mathrm{PhD}$ study.

\section{References}

[1] R. Singh, N. B. Dahotre, "Corrosion degradation and prevention by surface modification of biometallic materials.," J. Mater. Sci. Mater. Med., vol. 18, no. 5, pp. 725-51 (2007)

[2] M. Niinomi, M. Nakai, J. Hieda, "Development of new metallic alloys for biomedical applications.," Acta Biomater., vol. 8, no. 11, pp. 3888-903 (2012)

[3] K. Kato, A. Yamamoto, S. Ochiai, M. Wada, Y. Daigo, K. Kita, K. Omori, "Cytocompatibility and mechanical properties of novel porous 316L stainless steel," Mater. Sci. Eng. C (2013)

[4] M. Navarro, A. Michiardi, O. Castaño, J. A. Planell, "Biomaterials in orthopaedics.," J. R. Soc. Interface, vol. 5, no. 27, pp. 1137-58 (2008)

[5] P. Quadbeck, K. Kümmel, R. Hauser, G. Standke, "Open Cell Metal FoamsApplication-oriented Structure and Ma-terial Selection," Ifam-Dd.Fraunhofer.De (1966)

[6] Q. Chen, D. Mohn, and W. J. Stark, "Optimization of Bioglass ${ }^{\circledR}$ Scaffold Fabrication Process," J. Am. Ceram. Soc., vol. 94, no. 12, pp. 4184-4190 ( 2011)

[7] P. Quadbeck, K. Kümmel, R. Hauser, G. Standke, J. Adler, G. Stephani, B. Kieback, "Structural and Material Design of Open-Cell Powder Metallurgical Foams," Adv. Eng. Mater., vol. 13, no. 11, pp. 1024-1030 (2011)

[8] A. Nouri, P. Hodgson, C. Wen, "Biomimetic porous titanium scaffolds for orthopedic and dental applications," pp. 415-451 (2010)

[9] A. E. A. Maya, D. R. Grana, A. Hazarabedian, G. A. Kokubu, M. I. Luppo, G. Vigna, "Zr-Ti-Nb porous alloys for biomedical application," Mater. Sci. Eng. C, vol. 32, no. 2, pp. 321-329 (2012)

[10] A. Alem, M. D. Pugh, and R. A. L. Drew, "Open-cell reaction bonded silicon nitride foams: Fabrication and characterization," J. Eur. Ceram. Soc., vol. 34, no. 3, pp. 599-609 (2014)

[11] S. Ahmad, N. Muhamad, and A. Muchtar, "Development and Characterization of Titanium Alloy Foams," Int. J. Mech. Mater. Eng., vol. 5, no. 2, pp. 244-250 (2010)

[12] S. Won, H. Jung, M. Kang, H. Kim, Y. Koh, Y. Estrin, "Fabrication of porous titanium scaffold with controlled porous structure and net-shape using magnesium as spacer," Mater. Sci. Eng. C, vol. 33, no. 5, pp. 2808-2815 (2013)

[13] M. A. A. M. Nor, H. M. Akil, Z. A. Ahmad, "The effect of polymeric template density and solid loading on the properties of ceramic foam," Sci. Sinter., vol. 41, no. 3, pp. 319-327 (2009)

[14] M. J. Matos, S. Dias, F. A. C. Oliveira, "Macrostructural changes of polymer 
replicated open cell cordierite based foams upon sintering," vol. 106, no. 5, pp. 209-215 (2007)

[15] J. P. Li, C. A. V. A. N. Blitterswijk, K. D. E. Groot, "Factors having in ${ }^{-}$uence on the rheological properties of Ti6A14V slurry," vol. 5, pp. 951-958 (2004)

[16] J. Banhart, J. Baumeister, "Deformation characteristicsof metal foams," J. Mater. Sci., vol. 33, pp. 1431-1440 (1998)

[17] Q. Fu, M. N. Rahaman, B. Sonny Bal, R. F. Brown, D. E. Day, "Mechanical and in vitro performance of 13-93 bioactive glass scaffolds prepared by a polymer foam replication technique," Acta Biomater., vol. 4, no. 6, pp. 1854-1864 (2008) 